\section{Original Research}

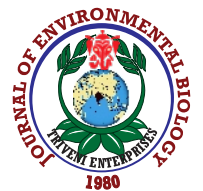

DOI : http://doi.org/10.22438/jeb/42/3(SI)/JEB-11

Journal website : www.jeb.co.in $\star$ E-mail : editor@jeb.co.in Journal of Environmental Biology

\title{
Prediction of leopard habitat suitability in Taman Negara main forest complex, Malaysia
}

\author{
N.F. Khodri', T. Lihan ${ }^{1 *}$, M.A. Mustapha', T.M. Taher', N.A.T. Arifin', N.I. Abdullah ${ }^{2}$ and S.M. Nor ${ }^{2}$ \\ 'Earth Science and Environmental Department, Faculty of Science and Technology, Universiti Kebangsaan Malaysia, 43600, Bangi, Malaysia \\ ${ }^{2}$ Biological Science and Biotechnology Department, Faculty of Science and Technology, Universiti Kebangsaan Malaysia, 43600,Bangi, Malaysia.
}

*Corresponding Author Email : matt@ukm.edu.my

\section{Abstract}

Aim: This research assessed the distribution of leopard to predict the habitat suitability in Taman Negara National Park and adjacent forest area.

Methodology: Environmental factors for habitat suitability were derived from geographical information system (GIS) data such as elevation, slope, landuse, distance from urban and distance from river. Leopard presence data from 1993 to 2008 were integrated with the environmental parameters using maximum entropy (MaxEnt) modeling to assess habitat suitability across the study area.

Results: The results showed that distance from river contributed the most $(39.3 \%)$ in the habitat suitability modeling followed by distance from urban $(31.4 \%)$, elevation (12.3\%), land use types (10.1\%), and slope (6.9\%). Distance from river and urban showed highest contribution that influenced leopard distribution in which most suitable habitat occurred in proximity with river and further from urban. Habitat suitability of leopard were distributed among $48 \%$ over $2,218,389$ ha of the study area.

Interpretation: The findings of this study provides knowledge on how the species move and exploit different habitat niches for more effective conservation management. It provide models for future wildlife conservation and urban planning.

Key words: Habitat suitability, Leopard, Geographical information system
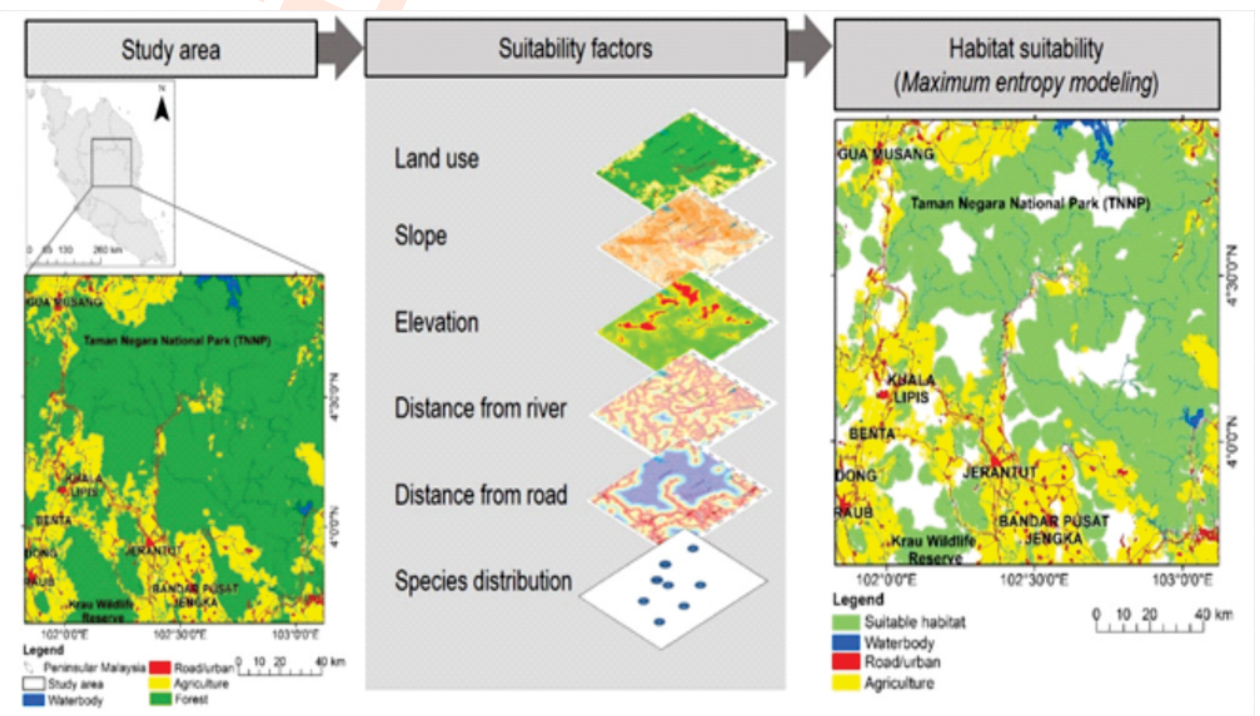

How to cite : Khodri, N.F., T. Lihan, M.A. Mustapha, T.M. Taher, N.A.T. Arifin, N.I. Abdullah and S.M. Nor: Prediction of leopard habitat suitability in Taman Negara main forest complex, Malaysia. J. Environ. Biol., 42, 806-811 (2021). 


\section{Introduction}

The leopard, Panthera pardus is the most widespread felid found in Africa and Asia, extending across the Middle East to the Pacific Ocean (Stein et al., 2016; Sunquist and Sunquist, 2002). Particularly in Southeast Asia, the leopard population is declining across their habitat range (Asrulsani et al., 2017; Ripple et al., 2014). More than $30 \%$ of suitable leopard habitat has been reduced worldwide within 22 years (Stein and Hayssen, 2013). Leopard population in Southeast Asia is found in Myanmar, Thailand, Vietnam, island of Java and Peninsular Malaysia. Interestingly, all leopard individuals recorded in Peninsular Malaysia have been of melanistic type, except for few individuals (Kawanishi et al., 2010; Tan et al., 2015). Leopard population in Peninsular Malaysia was assessed as endangered (DWNP, 2017). It is estimated that about 500-700 leopards are left in Peninsular Malaysia due to decline of suitable forest habitat (Chew, 2019).

Most of the remaining forest in Peninsular Malaysia is disturbed and affected by human activities (Azlan et al., 2006). In Malaysia, forest fragmentation occurring due to oil palm plantation, road and highways construction act as major threats for leopard to disperse from one fragmented area to other forested area (Azlan et al., 2006; Clements et al., 2014). Very less studies have been conducted on the population of leopard in Malaysia because studies on wildlife in tropical rain forest is difficult due to dense foliage coverage (Azlan et al., 2006; Ridout and Linkie, 2009). Thus, the best way to save these endangered species is to protect their habitat as threats to their survival has increased manifold over the years (Hedges et al., 2015; Mert and Yalçinkaya, 2017).

In this study, the habitat suitability of leopards in the largest protected area in the Taman Negara National Park (TNNP) forest complex was investigated. Taman Negara National Park is the core conservation area for wildlife including leopard and constitutes Malaysia's largest continuous tract of protected primary forest (434,000 ha) (Asrulsani et al., 2017; Ratnayeke et al., 2018). Taman Negara National Park covers three states of Pahang, Kelantan and Terengganu in the heart of Peninsular Malaysia and is regarded as the world's oldest tropical rainforest (Ibrahim and Hassan, 2011). The present study on leopards concern on the distribution, population size, genetic structure, prey preferences, temporal activity patterns, natural history and habitat selection (Asrulsani et al., 2017; Chew, 2019; Dutta et al., 2013; Hayward et al., 2006; Jacobson et al., 2016; Sanei et al., 2011; Simcharoen et al., 2008).

The environmental factors affecting the leopard habitat are anthropogenic disturbance, habitat fragmentation, proximity to water sources, proximity to human habitation, elevation and slope class (Abade et al., 2018; Gavashelishvili and Lukarevskiy, 2008; Ngoprasert et al., 2007).This study represents fresh attempt to document the habitat suitability of leopards in Taman Negara National Park and adjacent forest reserve in Peninsular Malaysia. Studies on the distribution and changes in leopard habitat distribution is crucial for conservation efforts (Yang et al., 2017). While understanding spatial patterns of species provide knowledge on how it moves and exploit different habitat niches (Roll et al., 2006). Therefore, information on leopard suitable habitat is needed to support effective conservation actions and stability of wildlife communities that depend on them (Gavashelishvili and Lukarevskiy, 2008; Lengyel et al., 2008). On view of the above, this study was conducted to predict leopard habitat suitability in Taman Negara National Park and adjacent forestareas.

\section{Materials and Methods}

Study area: This study was conducted at Taman Negara National Park, situated on the eastern region of Peninsular Malaysia that covers a total area of 2,218,389 ha (Fig.1). Taman Negara National Park consist of various forest types ranging from lowland to montane forest. The highest peak is situated at Gunung Tahanat at an elevation of $2,187 \mathrm{~m}$ (the highest mountain in Peninsular Malaysia).

Data collection: Primary and secondary data: Environmental parameters used for modeling were elevation, slope, land use types, distance from urban and river were processed using geographical information system (GIS) (ESRI ArcGIS 10.5). Contour data were obtained from the Department of Survey and Mapping Malaysia (JUPEM), which were further processed to generate elevation and slope layer. Recent Landsat 8 images of 2017 (path/row $127 / 59$ and 126/59, acquisition date 12 April 2017) were downloaded from United State Geological Survey used to produce land use map of the study area through supervised classification method. Classification of land use was verified through field observation. Ground truthing observations $(n=130)$ were collected during October 2017 with accuracy of $92 \%$. Distance from urban and distance from river was extracted from land use layer. Leopard presence data were collected through direct or indirect observations by the Department of Wildlife and National Parks from 1993 to 2008 (DWNP, 2010).The presence data used for modeling can be from records older than 3 leopard generations (21 years), showing regions where leopards may possibly occur (Jacobson et al., 2016).

Data analysis: GIS analysis and MaxEnt analysis: Environmental parameters and leopard presence data were processed using MaxEnt software version 3.3.3k (Computer Sciences Department, Princeton University, USA, 2004) with $70 \%$ training data (32 occurrence data) to predict habitat suitability and the remaining 30\% ( 13 occurrence data) were used for model testing. The maximum entropy modeling consisted algorithm that estimated the probability of species distribution based on species occurrence data and set of environmental variables (Phillips et al., 2006). 


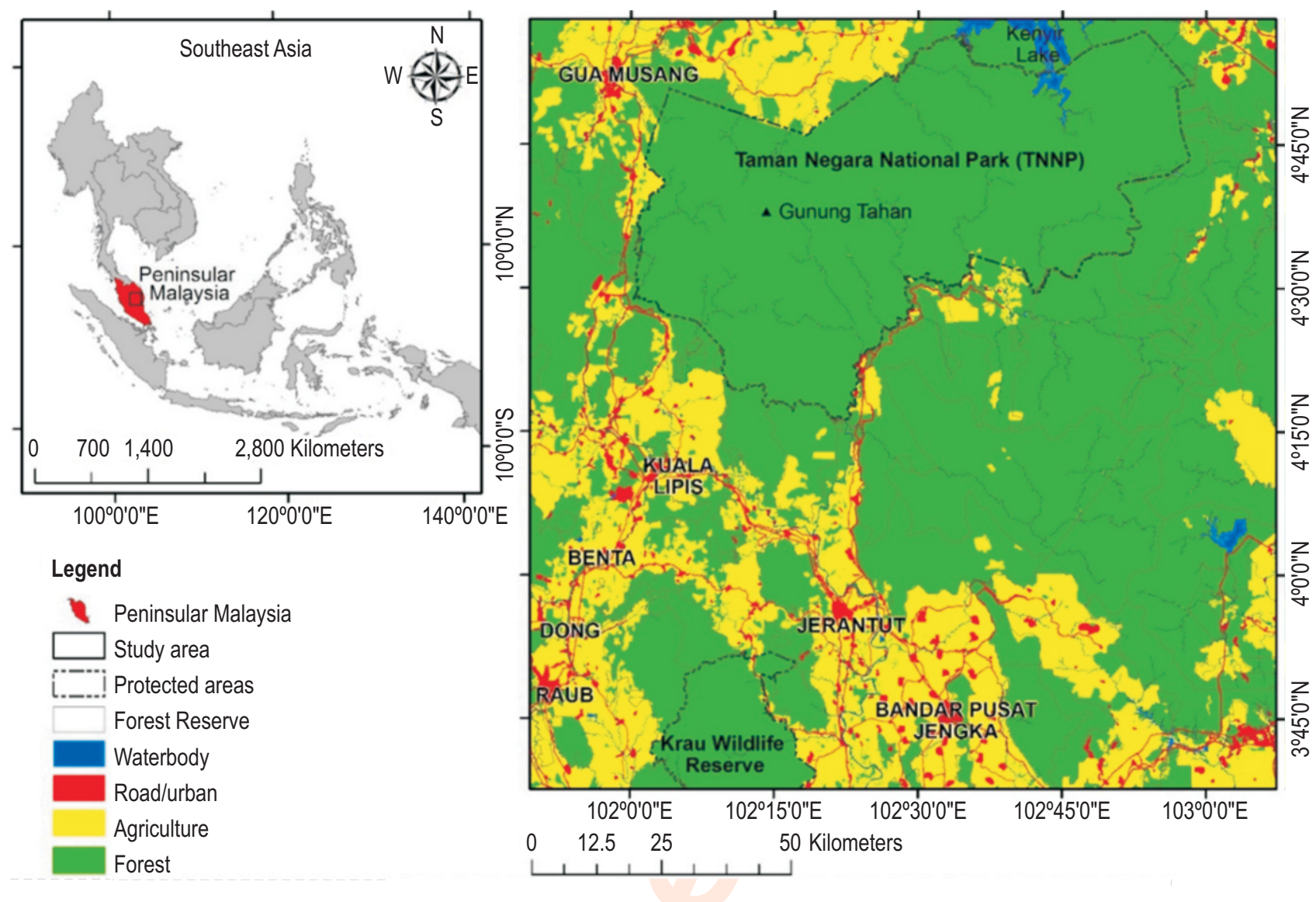

Fig. 1 : Location and land use category of study area. The map was derived from remote sensing data.

\section{Results and Discussion}

The relative percent contribution of environmental parameters was highest for distance from river $(39.3 \%)$, followed by distance from urban $(31.4 \%)$, elevation $(12.3 \%)$ land-use types (10.1\%), and slope (6.9\%) (Table 1).

These findings suggest that proximity to water source and urban areas exerted stronger influence than other environmental parameters and were the major limiting factors of leopard distribution across the study area. The data related to the presence of leopard showed occurrence near rivers because the suitable forest areas consist of many tributaries. Another study on leopards in Huai Kha Khaeng Wildlife Sanctuary, Thailand also found that areas close to stream channels were more favorable for leopards (Simcharoen et al., 2008). Leopards tend to favor riverine areas of high vegetative productivity to maximize hunting success (Pitman et al., 2017), therefore, areas closer to river has greater habitat use (Ngoprasert et al., 2007). The river proximity considered as a proxy to major traveling routes used by leopards and act as important landscape features for leopards when choosing a home range (Havmøller et al., 2019; Simcharoen et al., 2008).
The suitable habitat of leopards were located far away from urban areas. In this study, leopards were highly suitable at areas $14 \mathrm{~km}$ away from urban areas. Similar results were reported from Tanzania where significant strong negative relationship was observed between leopard site and habitats that were closer to households (Abade et al., 2018). Leopards tend to avoid areas nearby road although existence of road does not create a movement barrier to leopard (Ngoprasert et al., 2007). The existence of roads near forest reserve were most likely to promote forest conversion, poaching and trade in the region (Clements et al., 2014). Some of the areas adjacent to roads were suitable for leopards that indicate leopards were least sensitive to disturbance, which concurs with other studies that found high ability of leopards to survive and move through modified habitat (Dutta et al., 2013; Harihar et al., 2011). Locals are unaware of their presence in the close proximity of urban areas because they are nocturnal, secretive and less appealing, making their survival possible in human proximity as long as they have a safe retreat (Gavashelishvili and Lukarevskiy, 2008). In Jhalana Forest Reserve (India), humans and leopards coexist where leopards frequently encounter humans on the forest reserve fringes and in town or villages (Kumbhojkar et al., 2019). 
Table 1 : Environmental variable importance evaluated by percentage contribution and permutation importance. The permutation importance was used to assess variable importance.

\begin{tabular}{lll}
\hline Variables & Percent contribution $(\%)$ & Permutation importance $(\%)$ \\
\hline Distance from river & 39.3 & 38.9 \\
Distance from urban & 31.4 & 30.9 \\
Elevation & 12.3 & 16 \\
Land use types & 10.1 & 9.1 \\
Slope & 6.9 & 5.1 \\
\hline
\end{tabular}
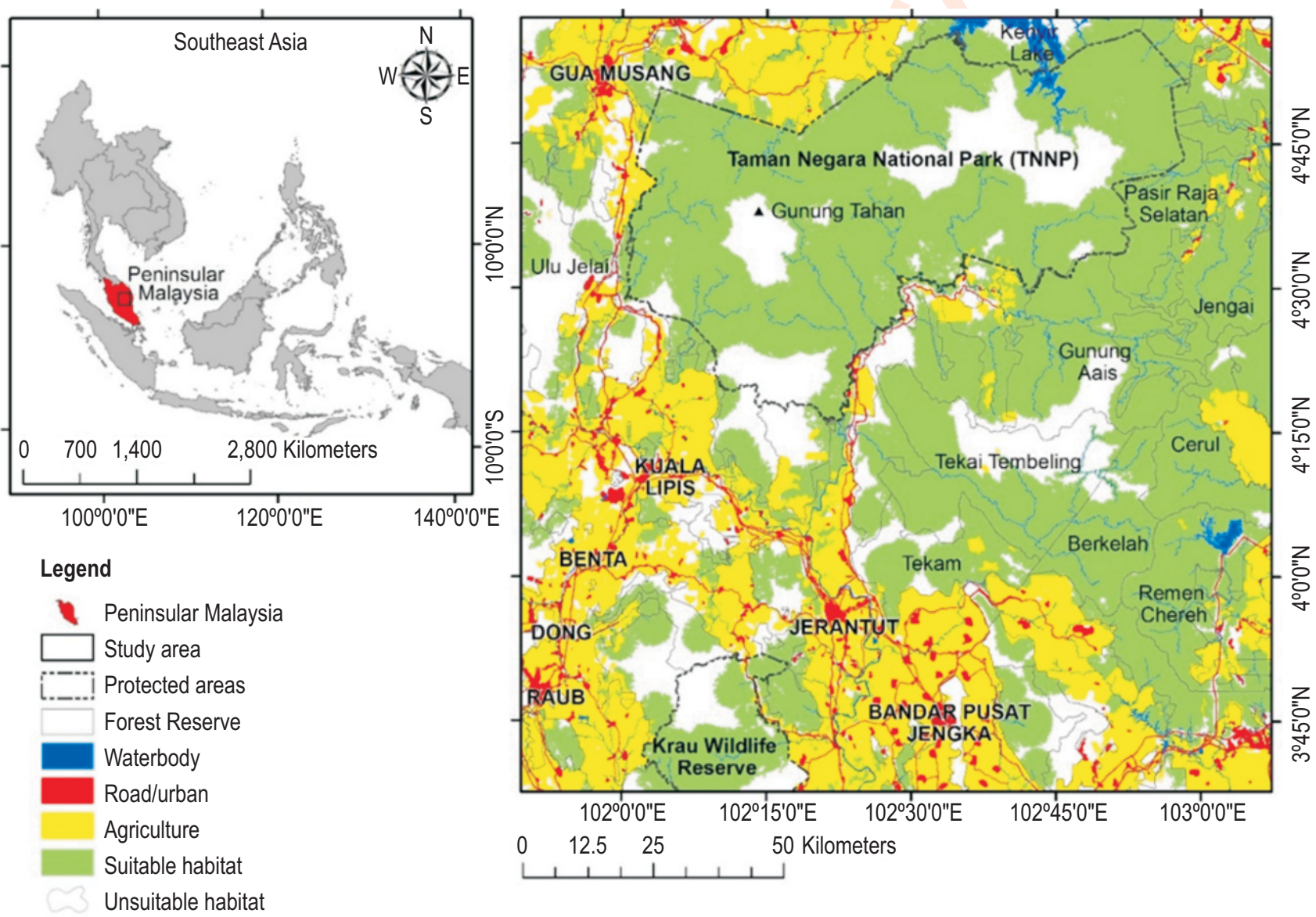

Fig. 2 : Panthera pardus habitat suitability in Taman Negara National Park and adjacent forest area derived from MaxEnt Model.

Most of the habitat suitability occurred in forest areas of Taman Negara National Park, Krau Wildlife Reserve, Tekai Tembeling Forest Reserve, Pasir Raja Selatan Forest Reserve, Jengai Forest Reserve, Gunung Aais Forest Reserve, Cerul Forest Reserve, Berkelah Forest Reserve, Remen Chereh Forest Reserve, Tekam Forest Reserve and small areas of Ulu Jelai Forest Reserve. Most Taman Negara National Park areas were suitable where macaques were abundant as food source for leopards (Chew, 2019). Leopards play an important ecological role of regulating their prey populations, especially wild ungulates (Dorresteijn et al., 2015). Dark colored (melanistic) leopards in Malaysia provides better visual concealment from larger predator such as tiger and prey, especially in the closed canopy of forest habitat (Asrulsani et al., 2017).

Leopard habitat suitability was less affected by slope with $7 \%$ contribution. Leopards were rarely found on high slopes, but suitable habitat of leopard covered large area regardless of steepness of the slope (Silva et al., 2017). Generally, leopards were found in or near rugged terrain, although in some cases they favored flat slope for easy movements (Gavashelishvili and Lukarevskiy, 2008; Simcharoen et al., 2008). Elevation had less influence on leopard habitat suitability with $12 \%$ contribution. Similar results were reported from Java island, Indonesia, with 
only $1.1 \%$ contribution for elevation (Wibisono et al., 2018). Leopards can adjust altitudes up to $5000 \mathrm{~m}$ or higher and inhabit hilly or mountain regions (Stein et al., 2016).

Leopard suitable habitats were distributed among 18 blocks over a total area of $2,218,389$ ha (Fig. 2). Total of $48 \%$ of the study area were suitable for leopard. Patches of unsuitable habitat were located in South and West direction of study area which mostly comprised urban areas such as Bandar Pusat Jengka, Jerantut and Kuala Lipis. Large areas of Bandar Pusat Jengka were less suitable for leopards due to close proximity to settlement area and large agriculture area mainly oil palm and rubber plantation that act as major threats to leopards (Azlan et al., 2006). This indicate that leopards avoid these areas due to human encroachment and urban development (Gavashelishvili and Lukarevskiy, 2008). The availability of food and water resources are scarce in the agriculture and settlement area, thus forcing leopards to migrate to adjacent forest areas (Alfred et al., 2012). Effect of urban and road development also resulted in fragmentation of forest areas suitable for leopards in the study area. Therefore, impact of construction of roads can be mitigated by improving forest connectivity to assist movement of leopard through fragmented habitat.

The area under the receiver operating characteristic curve (AUC) were used to model performance similar to other studies evaluating large scale habitat models developed in Maxent (Sulistyawan et al., 2017). The AUC ranged from 0 (worst model) to 1 (best model). Scores $>0.5$ indicate a model better than expected by random prediction (Elith et al., 2006). The mean AUC $\pm S E$ from the model was $0.80 \pm 0.061$ which indicates better discriminatory power of suitable versus unsuitable areas for the leopard. MaxEnt models with AUC scores $>0.75$ are considered potentially useful (Phillips et al., 2006).

This research demonstrates that the protected areas are important component of conservation strategies and can safeguard leopard population from pressures due to change in land use. Local government should plan and implement more strategies to conserve the remaining forests, including the National Park, in order to prevent depletion of wildlife habitat.

\section{Acknowledgments}

This research was part of Wildlife Protection and Conservation Project (Grant no: ST-2017-007). We would like to thank the Department of Wildlife and National Parks for providing wildlife data for this study. Thanks to Universiti Kebangsaan Malaysia for providing facilities needed.

\section{Add-on Information}

Authors' contribution : N.F. Khodri: Conceptualization, formal analysis, validation, Writing-original draft; T. Lihan: Conceptualization, data curation, writing- review and editing, methodology, supervision; M.A. Mustapha: Conceptualization, data curation, visualization; T.M. Taher, N.A.T. Arifin: Validation, methodology; N.I. Abdullah: Validation; S.M. Nor: Conceptualization, Visualization, Project administration.

Research content : The research content of manuscript is original and has not been published elsewhere.

Ethical approval : NotApplicable

Conflict of interest: The authors declare that there is no conflict of interest.

Data from other sources : NotApplicable

Consent to publish : All authors agree to publish the paper in Journal of Environmental Biology.

\section{References}

Abade, L., J. Cusack, R.J. Moll, P. Strampelli, A.J. Dickman, D.W. Macdonald and R.A. Montgomery: Spatial variation in leopard (Panthera pardus) site use across a gradient of anthropogenic pressure in Tanzania's Ruaha landscape. PLOS ONE, 13, 1-17 (2018).

Alfred, R., A.H. Ahmad, J. Payne, C. Williams, L.N. Ambu, P.M. How and $B$. Goossens: Home range and ranging behaviour of bornean elephant (Elephas maximus borneensi) females. PLOS ONE, 7, 212 (2012).

Asrulsani, J., K.A. Mohamed, I.S. Mohd, H. Rafhan, A. Halim, M.H. Saharudin, M. Fauzi and S. Samsuddin: Panthera pardus in Taman Negara Narional Park, Peninsular Malaysia. Wildlife Parks, 29, 23-29 (2017)

Azlan, M., J.B. Abd and G. Azad: Mammal diversity and conservation in a secondary forest in Peninsular Malaysia. Biodivers. Conserv., 15 1013-1025 (2006).

Chew, S.Y.: Natural history of the leopard (Panthera pardus) in Peninsular Malaysia. Malayan Nat. J., 71, 127-137 (2019).

Clements, G.R., A.J. Lynam, W.L. Yap, M. Goosem, S. Laurance, S. Lhota, D. Gaveau and W.F. Laurance: Where and how are roads endangering mammals in Southeast Asia's forests? PLOS ONE, 9 , $1-25(2014)$.

Dorresteijn, I., J. Schultner, D.G. Nimmo, J. Fischer, J. Hanspach, T. Kuemmerle, L. Kehoe and E.G Ritchie: Incorporating anthropogenic effects into trophic ecology: Predator-prey interactions in a human-dominated landscape. Proc. R. Soc. B., 282, 1-8 (2015).

Dutta, T., S. Sharma, J.E Maldonado, T.C. Wood, H.S. Panwar and J. Seidensticker: Fine-scale population genetic structure in a wideranging carnivore, the leopard (Panthera pardus fusca) in Central India. Divers. Distrib., 19, 760-771 (2013).

DWNP: Red List of Mammals for Peninsular Malaysia. $1^{\text {st } E d n ., ~}$ Department of Wildlife and National Parks, Malaysia (2010).

DWNP: Red List of Mammals for Peninsular Malaysia. $2^{\text {nd }} E d n$., Department of Wildlife and National Parks, Malaysia (2017).

Elith, J., C. Graham, R.P. Anderson, M. Dudik, S. Ferrier and A. Guisan: Novel methods improve prediction of species' distributions from occurrence data. Ecography, 29, 129-151 (2006).

Gavashelishvili, A. and V. Lukarevskiy: Modelling the habitat 
requirements of leopard Panthera pardus in West and Central Asia. J. Appl. Ecol., 45, 579-588 (2008).

Harihar, A., B. Pandav and S.P. Goyal: Responses of leopard Panthera pardus to the recovery of a tiger Panthera tigris population. J. Appl. Ecol., 48, 806-814 (2011).

Havmøller, R.W., S. Tenan, N. Scharff and F. Rovero: Reserve size and anthropogenic disturbance affect the density of an African leopard (Panthera pardus) meta-population. PLoS ONE, 14, 1-17 (2019).

Hayward, M.W., P. Henschel, J.O. Brien, M. Hofmeyr, G. Balme and G.I.H. Kerley: Prey preferences of the leopard (Panthera pardus). J. Zool., 270, 298-313 (2006).

Hedges, L., W.Y. Lam, A. Campos-Arceiz, D.M. Rayan, W.F. Laurance, C.J. Latham, S. Saaban and G.R. Clements: Melanistic leopards reveal their spots: Infrared camera traps provide a population density estimate of leopards in Malaysia. J.Wildl. Manage., 79, 846-853 (2015).

Ibrahim, Y., and M.S. Hassan: Tourism management at Taman Negara (National Park), Pahang, Malaysia: Conflict and synergy. J. Ritsumeikan Social Sci. Human., 3, 109-122 (2011).

Jacobson A.P., P. Gerngross, J.R. Lemeris Jr, R.F. Schoonover, C. Anco, C. Breitenmoser and S.M. Durant: Leopard (Panthera pardus) status, distribution, and the research efforts across its range. Peer J., 4, 1-28 (2016).

Kawanishi, K., M.E. Sunquist, E. Eizirik, A.J. Lynam, D. Ngoprasert, W.N. Wan Shahruddin, D.M. Rayan, D.S.K. Sharma and R. Steinmetz: Near fixation of melanism in leopards of the Malay Peninsula. $J$. Zool., 282, 201-206 (2010).

Kumbhojkar, S., R. Yosef and Y. Benedetti: Human-leopard (Panthera pardusfusca) co-existence in Jhalana Forest Reserve, India. Sustainability, 11, 3912-3926 (2019).

Lengyel, S., A. Kobler, L. Kutnar, E. Framstad, P.Y. Henry, V. Babij, B. Gruber, D. Schmeller and K. Henle: A review and a framework for the integration of biodiversity monitoring at the habitat level. Biodivers. Conserv., 17, 3341-3356 (2008).

Mert, A. and B. Yalçinkaya: Relationship between some wild mammals and forest structural diversity parameters. J. Environ. Biol.,38, 879-884 (2017).

Ngoprasert, D., A.J. Lynam and G.A. Gale: Human disturbance affects habitat use and behaviour of Asiatic leopard Panthera pardus in Kaeng Krachan National Park, Thailand. Oryx, 41, 343-351 (2007).

Phillips, S.B., V.P. Aneja, D. Kang and S.P. Arya: Maximum entropy modeling of species geographic distributions. Int. J. Global Environ. Iss., 6, 231-252 (2006).

Pitman, R.T., J. Fattebert, S.T. Williams, K.S. Williams, R.A. Hill, L.T.B. Hunter, H. Robinson, J. Power, L. Swanepoel, R. Slotow and G.A. Balme: Cats, connectivity and conservation: Incorporating data sets and integrating scales for wildlife management. J. Appl. Ecol., 54, 1687-1698 (2017).

Ratnayeke, S., F.T. Van Manen, G.R. Clements, N.A.M. Kulaimi and S.P. Sharp: Carnivore hotspots in Peninsular Malaysia and their landscape attributes. PLOS ONE, 13, 1-18 (2018).

Ridout, M.S. and M. Linkie: Estimating overlap of daily activity patterns from camera trap data. J. Agric. Biol. Environ. Stat., 14, 322-337 (2009).

Ripple, W.L., E.G. Ritchie, W.J. Ripple, M.P. Nelson, D.W. Smith, J. Berger, O.J. Schmitz, A.J. Wirsing, J.A. Estes, C.C. Wilmers, A.D. Wallach, B. Elmhagen, M. Hebblewhite and M. Letnic: Status and ecological effects of the world's largest carnivores. Science, 343, 151-162 (2014).

Roll, U., T. Dayan and N. Kronfeld-Schor: On the role of phylogeny in determining activity patterns of rodents. Evol. Ecol., 20, 479-490 (2006).

Sanei, A., M. Zakaria, E. Yusof and M. Roslan: Estimation of leopard population size in a secondary forest within Malaysia's capital agglomeration using unsupervised classification pugmarks. Trop. Ecol.,52, 209-217 (2011).

Silva, L.G., K. Kawanishi, P. Henschel, A. Kittle, A. Sanei, A. Reebin, D. Miquelle, A.B. Stein, A. Watson, B. Kekule, R.B. Machado and E. Eizirik: Mapping black panthers: Macroecological modeling of melanism in leopards (Panthera pardus). PLOS ONE, 12, 1-17 (2017).

Simcharoen, S., A.C.D. Barlow, A. Simcharoen and J.L.D Smith: Home range size and daytime habitat selection of leopards in Huai Kha Khaeng Wildlife Sanctuary, Thailand. Biol. Conserv., 141, 22422250 (2008).

Stein, A.B., V. Athreya, P. Gerngross, G. Balme and G. Balme: Panthera pardus. The IUCN Red List of Threatened Species. $17^{\text {th }}$ Meeting of the Conference of the Parties Johannesburg, South Africa (2016).

Stein, A.B. and V. Hayssen: Panthera pardus (Carnivora: Felidae). Mamm. Spec., 45, 30-48 (2013).

Sulistyawan, B.S., B.A. Eichelberger, P. Verweij, R.G.A. Boot, O. Hardian, G. Adzan and W. Sukmantoro: Connecting the fragmented habitat of endangered mammals in the landscape of Riau-Jambi-Sumatera Barat (RIMBA), Central Sumatra, Indonesia (connecting the fragmented habitat due to road development). Global Ecol. Conserv., 9, 113-130 (2017).

Sunquist, M.E. and F. Sunquist: Wild Cats of the World. $1^{\text {st } E d n ., ~ T h e ~}$ University of Chicago Press, London (2002).

Tan, C., K. Wei, J. Moore, S. Saaban, A. Campos-arceiz and D.W. Macdonald: The discovery of two spotted leopards (Panthera pardus) in Peninsular Malaysia. Trop. Conserv. Sci., 8, 732-737 (2015).

Wibisono, H.T., H.A. Wahyudi, E. Wilianto, I.M.R. Pinondang, M. Primajati, D. Liswanto and M. Linkie: Identifying priority conservation landscapes and actions for the critically endangered Javan leopard in Indonesia: Conserving the last large carnivore in Java Island. PLoS ONE, 13, 1-13 (2018)

Yang, H., A. Viña, Y. Tang, J. Zhang, F. Wang, Z. Zhao and J. Liu: Rangewide evaluation of wildlife habitat change: A demonstration using Giant Pandas. Biol. Conserv., 213, 203-209 (2017). 